\title{
AN EVALUATION OF MANUAL AND MECHANICAL METHODS TO IDENTIFY Candida SPP. FROM HUMAN AND ANIMAL SOURCES
}

\author{
Geraldo dos Santos OLIVEIRA(1), Elizabeth Teixeira RIBEIRO(2) \& Francisco de Assis BARONI(3)
}

\section{SUMMARY}

To compare two yeast identification methods, i. e, the manual and the VITEK mechanical methods, 62 clinical samples from hemocultures and animal sources were analyzed. After identification as Candida yeasts by the VITEK method, the strains were recharacterized using manual assimilation methods and sugar fermentation tests. Our findings reveal 58\% concurrent identification between the two methods for animal strains, and $51 \%$ for human hemoculture strains.

KEYWORDS: Candida spp.; Identification; Vitek method; Yeast.

\section{INTRODUCTION}

The increasing incidence of candidiasis has drawn the attention of scientific and medical staffs attempting to improve methods of studying Candida yeasts. The use of ever more powerful pharmaceutical agents as a result of therapeutic and as surgical techniques, particularly with regard to organ transplants and oncology have resulted in an increase in the detection of clinical candidiasis ${ }^{24}$. In many cases, contamination takes place through serotherapy or medical merchandise, or hospital practices, including handling by the medical professional ${ }^{5}$.

Although the acuteness of the pathology depends on the rate of alteration of a patient's immunological system ${ }^{7}$, it is well known that systemic infections by Candida spp. are among the greatest sources of weakness and death of immunodeficient patients. Further, Candida spp. is the fourth most common group of microorganisms isolated from human blood by Intensive Care Units (ICUs) ${ }^{1,2,8}$. Candidiasis represents around $80 \%$ of fungal hospital infections, and most of the cutaneous, oropharyngeal, and particularly vulvovaginal infection, reported at physicians meeting $\mathrm{s}^{3,13}$. In a survey carried out at a public hospital in São Paulo, Brazil ${ }^{18}, 75$ yeast samples isolated from patients blood revealed Candida albicans and $C$. parapsilosis as the most frequent species ( $38.7 \%$ and $30.7 \%$, respectively). The occurrence of chronic diseases such as cancer, diabetes and cardiopathies, together with the life style of the general population in major urban centers constitute other reasons for the great incidence of candidiasis ${ }^{1}$. Lack of vitamins has also been considered responsible for decreased human and animal immunological responses, as has the use of antibiotics in animal feed, which increases the occurrence of candidiasis in large and small animals ${ }^{6,20}$.
Candida species have been classified into twelve groups, according to physiological behavior, particularly as regards the assimilation of carbon and nitrogen sources. According to KURTZMAN \& FELL $(1998)^{12}$, although the genetic basis for species recognition within each group is still not clear, classification at the species level is possible owing to the ease of identification. However, while many species have been classified into more than one group, most species of clinical interest as regards humans and animals have been classified as group VI Candida yeasts.

To identify Candida species, particularly in immunodeficient patients, many hospitals and diagnostic centers employ the VITEK mechanical method, which provides rapid results. This method uses identification cards for Gram positive bacteria, Gram negative bacteria, sugar fermenting bacteria, non glucose fermenting bacteria, anerobic bacteria, Neisseria spp., Haemophilus spp. and yeasts. Acrylic cards including various sites containing biochemical tests are inoculated with hemoculture strains, and following a colorimetric, computerized reading, results are available between four and 18 hours later. Occasionally, tests have been performed together with others micromorphological techniques using light microscopy ${ }^{17}$.

Major benefits are provided when mechanical methods are used, including automation, incubation units associated with rapid readings, useful printed reports for epidemiological surveys, and pathogen counts allowing local sample use ${ }^{16}$. The use of results as expressed by percentages, the high cost of equipment and card kits, the separation between identification cards and sensitivity tests, the need for some manual tests, and difficult control quality constitute the main disadvantages ${ }^{10,19}$. However, alterations in inoculum concentration,

(1) MS-Fernandes Figueira Institute-IOF, Rio de Janeiro, RJ, Brasil.

(2) Departamento de Patologia Clínica, Fernandes Figueira Institute, IOF, Rio de Janeiro, RJ, Brasil.

(3) Environmental and Pathogenic Yeasts Laboratory-DMIV-UFRRJ, Rio de Janeiro, Brasil.

Correspondence to: Francisco de Assis Baroni, LLPA-DMIV-IV-UFRRJ, Campus Universitário, C. Postal 74.528, 23851-970 Seropédica, RJ, Brasil. Phone/Fax: 55.21.26821711. E-mail: Baroni@ufrrj.br 
sample contamination, lack of maintenance, use of poor quality reagents, an insufficient data base for identifying of certain species, and alterations in the interpretation of readings on colorimetric instrument screens often limit the correct identification of microorganisms by this mechanical system ${ }^{16,10}$.

In the present study, we evaluate the manual and VITEK mechanical methods to compare correct species identification and to establish the percentage of concurrence in 49 human and 12 animal yeast strains.

\section{MATERIALS AND METHODS}

1. Isolation and identification of yeast strains: This survey phase was performed at the Clinical Pathology Laboratory of Fernandes Figueira Institute, Fiocruz, Rio de Janeiro, Brazil (Laboratório de Patologia Clínica do Instituto Fernandes Figueira, Fiocruz). Human hemocultures exhibiting fungemia by yeasts, previously detected by the BACTEC mechanical test were evaluated. This method detects microorganisms by monitoring the $\mathrm{CO}_{2}$ produced by microbial metabolism. The cultures were immediately reisolated on Sabouraud dextrose agar medium containing chloramphenicol $0.02 \%$, and incubated at $37{ }^{\circ} \mathrm{C}$ for $24-48 \mathrm{~h}$ for micro and macro analyses. The latter analysis was performed by light microscopy on blue cotton lactophenol stained slides to reveal hyphae and pseudohyphae. Strains identified as Candida spp. were submitted to VITEK mechanical tests in the same laboratory.

2. Identification by the traditional method: After classification as a Candida yeast by the VITEK method, the strains were recharacterized by manual assimilation methods and sugar fermentation, according to KURTZMAN \& FELL (1998) ${ }^{12}$. This phase of study was carried out at the Environmental and Pathogenic Yeasts Laboratory of the Universidade Federal Rural do Rio de Janeiro (LLPA/ UFRRJ), Seropédica, Rio de Janeiro, Brazil. All strains were held at the LLPA/UFRRJ.

2.1. Micromorphology: The strains were firstly submitted to typical, micromorphological observation and germinative tube production tests, as well as for chlamydoconidia and blastoconidia on rice agar. Germinative tube production tests were performed using sterilized equine serum incubated at $37{ }^{\circ} \mathrm{C}$ for three $\mathrm{h}$, while chlamydoconidia and blastoconidia production tests were performed on rice agar in Petri dishes $\left(50 \mathrm{~mm}\right.$ diameter), incubated at $30^{\circ} \mathrm{C}$. Light microscopic examination was performed during the first $78 \mathrm{~h}$. Other physiological tests such as fungal growth on Sabouraud dextrose agar containing $0.01 \%$ or $0.1 \%$ cycloheximide as well as growth tests at $37^{\circ} \mathrm{C}$ and at $40{ }^{\circ} \mathrm{C}$ also were performed.

2.2. Fermentation: Sugars such as raffinose, glucose, sucrose, trehalose, lactose, maltose and galactose, together with peptone from casein $1 \%$ in distilled water, distributed in standard assay tubes containing a Durham tube were employed as substrates in the sugar fermentation tests. A $1.5 \mathrm{~mL}$ aliquot of each sugar solution containing $6 \%$ sugar, and sterilized by filtration was placed in each tube to produce a data set from seven different carbon sources for each sample. The samples were inoculated using a $200 \mu \mathrm{L}$ aliquot in each tube, incubated at $37^{\circ} \mathrm{C}$, and readings taken after $48 \mathrm{~h}$; negative cases were accompanied for up to 15 days.
2.3. Assimilation: For the nitrogen source assimilation tests, Yeast Carbon Base (YCB-Difco Laboratories) was used, as was Yeast Nitrogen Base (YNB-Difco Laboratories) for the carbon source assimilation tests; both tests were performed according to the Difco Laboratories Instructions Guide employing $20 \mathrm{~mL}$ aliquots per tube. Each yeast sample was previously streaked on $4 \%$ Sabouraud dextrose agar to evaluate cell viability. The tests used a $1 \mathrm{~mL}$ aliquot from these samples prepared in saline solution, equivalent to five degrees on the McFarland scale, and were placed in empty Petri dishes. The aliquots were immediately covered with liquified YNB or YCB and cooled to $50{ }^{\circ} \mathrm{C}$. After adding the medium, and homogenizing/solidification, the carbon or nitrogen sources were applied at different sites on the medium. The Petri dishes were identified individually and were incubated at $37{ }^{\circ} \mathrm{C}$ for up to 10 days. Positive results for both samples were revealed by yeast growth at the sites of application.

\section{RESULTS}

Table 1 reveals a concurrence of $58 \%$ between both methods for the animal yeast strains, and $51 \%$ for the human hemoculture strains. When all strains are considered together, a concurrence of $53.2 \%$ was found.

These findings demonstrate that concurrent identification when using both methods is greater for the animal strains. Further coincident percentage identification is greatest for Candida parapsilosis.

\section{DISCUSSION}

To identify yeasts at the species level has become an important undertaking, particularly when clinical microbiology laboratories are concerned. Since the advent of Aids and its causes and incidence, corticosteroid use and different therapeutic procedures, in addition to the increase in inherited pathologies, have attained the greatest incidence of nosocomial fungal infection, particularly by Candida albicans, but including non albicans species such as $C$. parapsilosis, C. tropicalis and C. glabrata $^{23}$. Even with the widespread use of antifungal agents in HIV patients, those with myeloproliferative diseases, and organ transplant patients, these events have contributed to the emergence of microorganisms, requiring appropriate and rapid identification of the etiologic agent. Monoculture of different identification stages of Candida species is very important; however, such staging cannot be performed using the VITEK system. The VITEK method was presumed to be the most accurate method, but according VERWEIJ et al. (1999)22, evaluating seven different identification methods for Candida, Auxacolor and API were demonstrated to be the best methods. This fact is of some relevance given that of 15 Candida albicans samples identified by the VITEK mechanical system in the VERWEIJ et al. (1999)22 survey, 10 were corroborated by the traditional method, and, owing to the lack of some tests, concurrent identification of five samples was found.

Using analyses employing both methods, various indexes of concurrence between identification tests have been reported. GUELFAND et al. (2003) $)^{11}$ reported $90 \%$ concurrence with morphological tests on Corn Meal Agar, while SOOD et al. $(2000)^{21}$ demonstrated $68 \%$ concurrence. VERWEIJ et al. (1999) ${ }^{22}$ analyzing and comparing seven methods, including the VITEK technique, 
OLIVEIRA, G.S.; RIBEIRO, E.T. \& BARONI, F.A. - An evaluation of manual and mechanical methods to identify Candida spp. from human and animal sources. Rev. Inst. Med. trop. S. Paulo, 48(6): 311-315, 2006.

Table 1

Comparison of the identification of Candida spp. in samples performed using manual and automated methods

\begin{tabular}{|c|c|c|c|c|c|c|c|}
\hline $\begin{array}{l}\text { Registration } \\
\text { number }\end{array}$ & Origin & $\begin{array}{l}\text { VITEK } \\
\text { identification }\end{array}$ & $\begin{array}{l}\text { Manual } \\
\text { identification }\end{array}$ & $\begin{array}{l}\text { Registration } \\
\text { number }\end{array}$ & Origin & $\begin{array}{l}\text { VITEK } \\
\text { identification }\end{array}$ & $\begin{array}{l}\text { Manual } \\
\text { identification }\end{array}$ \\
\hline $12 \mathrm{~A}$ & Control & C. albicans & C albicans & 6544 & IFF & C. albicans & C. albicans \\
\hline G I & $\mathrm{AN}$ & C. albicans & C. albicans & 6742 & IFF & C. parapsilosis & C. parapsilosis \\
\hline G III & AN & C. albicans & C. albicans & 6809 & IFF & C. parapsilosis & $\begin{array}{l}\text { C. guilliermondii var. } \\
\text { guilliermondii }\end{array}$ \\
\hline $\mathrm{P} 1 \mathrm{C} 16$ & $\mathrm{AN}$ & C. guilliermondii & C. maltosa & 6840 & IFF & C. parapsilosis & C. parapsilosis \\
\hline P19 D14 & $\mathrm{AN}$ & C. parapsilosis & C. parapsilosis & 6851 & IFF & C. parapsilosis & C. parapsilosis \\
\hline P20 B15 & $\mathrm{AN}$ & C. guilliermondii & C. lusitaniae & 6974 & IFF & C. parapsilosis & C. parapsilosis \\
\hline P20 E16 & $\mathrm{AN}$ & C. famata & NAC & 6975 & IFF & C. parapsilosis & C. parapsilosis \\
\hline P20 F15 & $\mathrm{AN}$ & C. parapsilosis & C. parapsilosis & 7015 & IFF & C. guilliermondii & Group VI - SD \\
\hline P20 G16 & $\mathrm{AN}$ & C. famata & NAC & 7185 & IFF & C. parapsilosis & C. parapsilosis \\
\hline P5 A14(1) & $\mathrm{AN}$ & C. parapsilosis & C. parapsilosis & 7210 & IFF & C. parapsilosis & C. parapsilosis \\
\hline P5 A14(2) & $\mathrm{AN}$ & C. parapsilosis & C. parapsilosis & 7224 & IFF & C. parapsilosis & Group IV \\
\hline P9 A16(1) & $\mathrm{AN}$ & C. parapsilosis & C. parapsilosis & 7247 & IFF & C. famata & NAC \\
\hline P9 A16(2) & $\mathrm{AN}$ & C. tropicalis & C. lusitaniae & 7271 & IFF & C. parapsilosis & C. parapsilosis \\
\hline 4844 & IFF & C. albicans & Group VI & 7280 & IFF & C. parapsilosis & Group IV \\
\hline 4854 & IFF & C. albicans & C. parapsilosis & 7285 & IFF & C. albicans & C. tropicalis \\
\hline 5194 & IFF & C. tropicalis & C. parapsilosis & 7336 & IFF & C. albicans & C. parapsilosis \\
\hline 5217 & IFF & C. parapsilosis & C. parapsilosis & 7338 & IFF & C. lusitaniae & Group VI \\
\hline 5595 & IFF & C. tropicalis & C. tropicalis & 7352 & IFF & C. guilliermondii & Group VI \\
\hline 5641 & IFF & C. albicans & C. parapsilosis & 7450 & IFF & C. guilliermondii & Group III \\
\hline 5727 & IFF & C. guilliermondii & C. palmioleophila & 7643 & IFF & C. parapsilosis & Group VI \\
\hline 5881 & IFF & C. parapsilosis & C. parapsilosis & 7651 & IFF & C. lusitaniae & C. lusitaniae \\
\hline 5882 & IFF & C. parapsilosis & C. palmioleophila & 7687 & IFF & C. albicans & C. albicans \\
\hline 5956 & IFF & C. parapsilosis & C. parapsilosis & 7717 & IFF & C. guilliermondii & C. parapsilosis \\
\hline 5990 & IFF & C. parapsilosis & C. palmioleophila & 7833 & IFF & C. albicans & C. albicans \\
\hline 6335 & IFF & C. tropicalis & C. tropicalis & 7835 & IFF & C. albicans & C. albicans \\
\hline 6362 & IFF & C. tropicalis & Group III & 7906 & IFF & C. parapsilosis & C. parapsilosis \\
\hline 6400 & IFF & C. famata & NAC & 7925 & IFF & C. albicans & C. albicans \\
\hline 6409 & IFF & C. famata & NAC & 7952 & IFF & C. albicans & C. albicans \\
\hline 6413 & IFF & C. tropicalis & C. parapsilosis & 7999 & IFF & C. tropicalis & C. parapsilosis \\
\hline 6427 & IFF & C. parapsilosis & C. parapsilosis & 8026 & IFF & C. albicans & C. albicans \\
\hline 6533 & IFF & C. parapsilosis & C. parapsilosis & 8027 & IFF & C. parapsilosis & C. parapsilosis \\
\hline
\end{tabular}

AN: Animal (UFRRJ origin), IFF: Fernandes Figueira Institute (all strains were held at the Pathogenic and Environmental Yeasts Laboratory - DMIV - UFRRJ), NAC: Not Accomplished, Group III, Group IV ... : Belonging to one of the 12 physiological groups of KURTZMAN \& FELL (1998), without specific identification.

demonstrated concurrence ranging from $59.6 \%$ to $80 \%$. WADLIN et al. $(1999)^{23}$ studying concurrence among three commercial methods (Rapid Yeast Plus System, API 20C Aux and VITEK) against the traditional auxanographic method and the microscopic method encountered $86 \%$ concurrent identification. A similar percentage between this method and API $20 \mathrm{C}$ Aux was also reported by these authors. SOOD et al. $(2000)^{21}$ found $68 \%$ concurrence between the VITEK and the traditional method.

It seems clear that the VITEK system, which requires only a single yeast suspension inoculation on a single plate (acrylic card) including automatized test readings after 48 hours can be considered the most practical and rapid test system. Owing to the single handling of the culture (suspension manufacturing and setting of the plate), this system is safer and avoids operator errors concerning interpretation of test results with a diminished or weak reaction. However, the VITEK mechanical system does not work well, for performing starch, ramnose, inulin and peptone assimilation tests. Similarly, fungal growth at $37^{\circ} \mathrm{C}$ and $40{ }^{\circ} \mathrm{C}$ for general species identification is most important for identification keys.

It may oppose that the automatized mechanical method was developed mainly for detecting Candida species from Section VI. However, it should not be forgotten that, despite the advent of corticotherapics and particularly immunosuppressive diseases, yeast species that previously could not be isolated in many pathologies, currently can be cultured. Among the new microorganisms isolated from infectious diseases and low immunity patients, $C$. dubliniensis (also germinative tube producer) probably has not been identified by the VITEK system.

VERWEIJ et al. (1999) ${ }^{22}$ remark that all the systems tested, including the VITEK system to identify species such as Candida norvegensis, C. catenulate, C. haemulonii and C. dubliniensis have 

Paulo, 48(6): 311-315, 2006.

failed. GRAF et al. (2000) $)^{9}$ using the VITEK system, were unable to unequivocally identify $C$. inconspicua and $C$. norvegensis, suggesting that in the future, it may be necessary to perform complementary tests.

According to DOOLEY et al. (1999) ${ }^{4}$ comparing fast identification by the VITEK system with the API 20C system (which includes biochemical tests and morphology), the VITEK system was considered successful in yeast identification, attaining 93\% isolation. However, to identify a few isolated species such as C. krusei (42\%), C. lambica (80\%), Trichosporon beigelii (88\%) and Cryptococcus non neoformans species $(83 \%)$, the VITEK mechanical system failed completely.

Our comparison between mechanical and manual identification results reveals some strains to be strain 7450 , previously classified as C. guilliermondii, although the tests performed at LLPA demonstrated this strain as belonging to Section III. While some species pertain to more than one group, this species is unable to assimilate erythritol, a good justification for its exclusion from Section III. The same situation holds with regard to strain 6362 , classified by the VITEK system as Candida tropicalis.

A poorly interpreted test can lead to an erroneous conclusion regarding positive erythritol assimilation, and would be sufficient to classify this species to Section III. However, it should be emphasized that $C$. guilliermondii var. guilliermondii, while able to ferment glucose as well as all the sugars from key VI, including soluble starch (except for the mechanical system), cannot grow on vitamin free medium. Using the traditional method, this strain could not be identified as $C$. guilliermondii either by positive erythritol assimilation or by cellobiose and sucrose fermentation.

The VITEK mechanical system provides test results as percentages, and also furnishes reports with profuse information concerning which supplementary tests are necessary.

In certain cases, using identification by the traditional method, a single sample was classified as C. palmioleophila, but, when submitted to the mechanical test, the same sample was identified as $C$. parapsilosis. NAKASE et al. $(1988)^{14}$ verified $40.3 \%$ concurrence of DNA in these two species, and this genetic concurrence may underlie some degree of phenotypic correlation. While C. palmioleophila is similar to C. famata and C. saitoana, it can be distinguished from them on the basis of its high maximum growth temperature.

One of the strains classified as Candida famata by the mechanical system exhibited behavior different from that predicted. According to KURTZMAN \& FELL (1998) ${ }^{12}$, due to variability in many tests, Candida famata has not been included in the general classification key. NAKASE \& SUZUKI's (1985) ${ }^{15}$ survey reported negative or soft sugar fermentation and unstable (positive or negative) assimilation tests for at least eleven sugars tested.

This suggests the need for several complementary tests, not available in our laboratory when these experiments were carried out. Thus, in this case we have not compared our results. However, the identification of this species is quite questionable. By the traditional system, it would be important to perform several tests, as well as a comparison with the standard strain, for reliable identification.

\section{RESUMO}

\section{Avaliação de métodos de identificação de leveduras do gênero Candida de origem humana e animal}

Objetivando comparar os resultados de dois métodos de identificação, o manual e o método automatizado VITEK, foram analisadas 62 amostras clínicas isoladas de hemoculturas humanas e de origem animal. Estas amostras, após serem identificadas como Candida spp. pelo método automatizado VITEK, foram recaracterizadas com a utilização de métodos manuais de assimilação e fermentação de fontes carbonadas. Os resultados demonstraram uma relação de $58 \%$ de identificações coincidentes entre os dois métodos para as amostras de origem animal e de $51 \%$ para as amostras de hemoculturas humanas.

\section{REFERENCES}

1. CANDIDO, R.C.; FISCHMAN, O.; ITO, I.Y. \& PAULA, C.R. - Candida albicans: biotyping by susceptibility to antimycotics. Rev. Microbiol. (S. Paulo), 27: 83-86, 1996.

2. COLOMBO, A.L. \& GUIMARÃES, T. - Epidemiology of hematogenous infections due to Candida spp. Rev. Soc. bras. Med. trop., 36: 599-607, 2003.

3. COLOMBO, A.L.; NUCCI, M.; SALOMÃO, R. et al. - High rate of non-albicans candidemia in Brazilian tertiary care hospitals. Diagn. Microbiol. infect. Dis., 34: 281-286, 1999

4. DOOLEY, D.P.; BECKIUS, M.L. \& JEFFREY, B.S. - Misidentification of clinical yeast isolates by using the update VITEK Yeast Biochemical Card. J. clin. Microbiol., 32: 2889-2892, 1994

5. FRIDKIN, S. \& JARVIS, W.R. - Epidemiology of nosocomial fungal infections. Clin. Microbiol. Rev., 9: 499-511, 1996.

6. GARCÍA, M.E. \& BLANCO, J.L. - Principales enfermedades fúngicas que afectan a los animales domésticos. Rev. iberoamer. Micol., 17: S2-S7, 2000.

7. GIUSIANO, G.E. - Infecciones por levaduras en pacientes pediátricos hospitalizados. An. Inst. Med. reg. Univ. nac. Nord. (Chaco, Argentina), p. 5-11, 1999.

8. GODOY, P.; TIRABOSCHI, I.N.; SEVERO, L.C. et al. - Species distribution and antifungal susceptibility profile of Candida spp. bloodstream isolates from Latin American hospitals. Mem. Inst. Oswaldo Cruz., 98: 401-405, 2003.

9. GRAF, B.; ADAM, T.; ZILL, E. \& GOBEL, U.B. - Evaluation of the VITEK system for rapid identification of yeasts and yeast-like organisms. J. clin. Microbiol., 38: 1782$1785,2000$.

10. GRANT, C.E.; SEWELL, D.L.; PFALLER, M.; BUMGARDNER, R.V. \& WILLIAMS, J.A. - Evaluation of two commercial systems for identification of coagulase-negative Staphylococci to species level. Diagn. Microbiol. infect. Dis., 18: 1-5, 1994.

11. GUELFAND, L.; GRISOLIA, P.; BOZZANO, C. \& KAUFMAN, S. - Comparison of methods for the identification of the most common yeasts in the clinical microbiology laboratory. Rev. argent. Microbiol., 35: 49-53, 2003.

12. KURTZMAN, P.C. \& FELL, J.W. - The yeasts, a taxonomic study. 4. ed. Amsterdam, Elsevier, 1998.

13. MAGLIANI, W.; CONTI, S.; SALATI, A. et al. - New strategies for treatment of Candida vaginal infections. Rev. iberoamer. Micol., 19: 144-148, 2002.

14. NAKASE, T.; ITOH, M.; SUZUKI, M.; KOMAGATA, K. \& KODAMA, T. - Candida palmioleophila sp. Nov., a yeast capable of assimilating crud palm oil, formerly identified as Torulopsis candida. J. gen. appl. Microbiol., 34: 493-498, 1988. 
15. NAKASE, T. \& SUZUKI, M. - Taxonomic studies on Debaryomyces hansenii (Zopf) Lodder et Kreger - van Rij and related species. I. Chemotaxonomic investigations. J. gen. appl. Microbiol., 31: 49-69, 1985

16. OBLACK, D.L.; RHODES, J.C. \& MARTIN, W.J. - Clinical evaluation of the auto microbic system yeast biochemical card for rapid identification of medically importan yeasts. J. clin. Microbiol., 13: 351-355, 1981

17. PFALLER, M.A.; SAHM, D.; O'HARA, C.M. et al. - Comparison of the autoSCAN W/A rapid bacterial identification system and the Vitek AutoMicrobic system for identification of Gram-negative bacilli. J. clin. Microbiol., 29: 1422-1428, 1991.

18. RUIZ, L.S.; SUGIZAKI, M.F.; MONTELLI, A.C. et al. - Fungemia by yeasts in Brazil: occurrence and phenotypic study of strains isolated at the Public Hospital, Botucatu, São Paulo. J. Mycol. méd., 15: 13-21, 2005.

19. SADER, H.S. \& MIRANDA, E.A. - Limitações dos métodos automatizados em Microbiologia. In: JORNADA DE INICIAÇÃO CIENTÍFICA, 4., Botucatu, EPM - UFESP, 1999. Anais. p. 14-16.
20. SATO, Y.; AOYAGI, T.; KOBAYASHI, T. \& INOUE, J. - Occurrences of candidiasis in a Fisher's lovebird and a budgerigar. J. Vet. med. Sci., 63: 939-941, 2001.

21. SOOD, P.; MISHRA, B.; DOGRA, V. \& MANDAL, A. - Comparison of Vitek Yeast Biochemical Card with conventional methods for speciation of Candida. Indian J. Path. Microbiol., 43: 143-145, 2000.

22. VERWEIJ, P.E.; BREUKER, I.M.; RIJS, A.J. \& MEIS, J.F. - Comparative study of seven commercial yeast identification systems. J. clin. Path., 52: 271-273, 1999.

23. WADLIN, J.K.; HANKO, G.; STEWART, R.; PAPE, J. \& NACHAMKIN, I. - Comparison of three commercial systems for identification of yeasts commonly isolated in the clinical microbiology laboratory. J. clin. Microbiol., 37: 1967-1970, 1999.

24. WANSLEY, D.L.; BANERJEE, S. \& McGEADY, P. - Separation of the filamentous and cellular yeast forms of $C$. albicans following serum induction. J. microbiol. Meth., 55: 321-323, 2003

Received: 29 September 2005

Accepted: 12 May 2006 